\title{
GAYA KEPEMIMPINAN DAN KEPUSAN KERJA DI PERUM PERUMNAS REGIONAL III
}

\author{
Lia Kusuma Pratiwi \& Herwindo Haribowo \\ Jurusan Psikologi, Universitas Negeri Jakarta
}

liakusuma27@gmail.com

\begin{abstract}
The aim of this study is to know the difference of leadership styles and job satisfaction in PERUM PERUMNAS REGIONAL III. The research was held in PERUM PERUMNAS REGIONAL III, Jakarta on June - September 2013. This research used quantitative ex-post facto research method. Data were collected using scale of LBDQ XII (Leadership Behavior Description Questionnaire) and scale JSS (Job Satisfaction Survey), were assessed among 129 outpatients. Statistical analysis was done using the Analysis of Varians with SPSS version 17.00. The results of the study shows that on the interaction between initiating structure and consideration to job satisfaction significance at the level of 0,044 . This shows that there are significant differences in the job satisfaction in terms of the interaction between initiating structure leadership style and consideration.
\end{abstract}

Keyword : Initiang Structure, Consideration, Job Satisfaction

\section{Pendahuluan}

Gaya kepemimpinan merupakan suatu cara yang digunakan oleh seorang pemimpin dalam mempengaruhi perilaku orang lain (Thoha, 2012). Dalam kepemimpinan yang efektif terdapat beberapa gaya kepemimpinan yang diterapkan dalam menjalankan perusahaannya, salah satunya gaya kepemimpinan berdasarkan studi Ohio (Ohio State Leadership Studies) yang dilakukan oleh para peneliti dari universitas tersebut pada tahun 1950an. Studi Ohio mengungkapkan bahwa ada dua gaya kepemimpinan yang penting: gaya kepemimpinan Initiating Structure dan gaya kepemimpinan Consideration (Fleishman, 1957; Halpin and Winer, 1957; Hemphill and Coons, 1957). Pemimpin yang mengadopsi gaya kepemimpinan initiating structure akan lebih berfokus pada peranperan bawahannya ke arah pencapaian tujuantujuan. Sementara pemimpin yang mengadopsi gaya kepemimpinan consideration akan lebih menekankan pada tingkat dimana seorang pemimpin bertindak dalam cara yang hangat dan supportive serta menunjukan perhatian kepada bawahan.
Pada masing-masing gaya kepemimpinan dari Ohio ini dapat diterapkan oleh atasan laki-laki ataupun perempuan. Akan tetapi, terdapat perebedaan antara laki-laki dan perempuan yaitu faktor biologis. Berbagai penelitian menunjukan secara menyakinkan bahwa terdapat berbagai karakteristik dengan tipikal gender, yaitu maskulin dan feminim (Bem, 1984; Eagly \& Wood, 1999). Untuk laki-laki disebut maskulin dengan karakteristik kuat, dominan, asertif, sedangkan perempuan disebut feminim dengan karakteristik perhatian, sensitif, dan ekspresif secara emosional. Dengan apa yang telah dijelaskan diatas maka akan terlihat gaya kepemimpinan yang digunakan berbeda sesuai dengan gender dan apa yang dirasakan oleh karyawan dalam bekerja dengan atasan laki-laki ataupun perempuan akan berbeda. Dalam sebuah penelitian yang menjaring 3000 pria dan wanita, mendapati tiga perempat $(75 \%)$ lakilaki lebih senang bekerja untuk atasan laki-laki. Dua pertiga $(63 \%)$ wanita lebih memilih atasan laki-laki karena mereka biasa to the point, berbicara langsung pada intinya, sehingga lebih mudah dihadapi. Atasan pria juga tidak mengalami mood swing, mereka juga lebih logis, demikian menurut 
$14 \%$ responden. Seperempat $(25 \%)$ responden perempuan merasa atasan perempuan sering membawa masalah pribadi ke kantor. Sepertiga $(33 \%)$ dari mereka juga mengatakan bahwa perempuan yang memiliki kekuasaan sering merasa terancam oleh bawahannya. Meskipun demikian, penelitian ini juga menghasilkan responden yang "pro" dengan atasan perempuan. Mereka yang memilih atasan perempuan mengatakan bahwa perempuan justru lebih mudah didekati dan ramah. Dari penelitian ini menunjukan bahwa rata-rata karyawan memiliki dua atasan perempuan dan tiga atasan laki-laki. Sepertiga responden pernah mengundurkan diri dari perusahaan karena tidak menyukai atasannya dan mayoritas dari responden perempuan mengaku keluar dari pekerjaan karena tidak cocok dengan atasan perempuan (kompas.com)

Dari penelitian diatas, keluarnya seorang karyawan dari pekerjaannya disebabkan oleh ketidakpuasan yang dirasakan karyawan dalam pekerjannya dan hal ini dikarenakan faktor atasan. Secara umum, kepuasan kerja dapat berupa perasaan seseorang terhadap pekerjaan mereka dan aspek-aspek yang berkaitan dengan pekerjaan mereka. Perasaan tersebut mengenai kesukaan (kepuasan) atau ketidaksukaan (ketidakpuasan) seseorang terhadap pekerjaannya (Spector, 1977).

Dalam kepuasan kerja terdapat aspek-aspek yang mendukung, yaitu gaji, promosi, supervisi, tunjangan, penghargaan, prosedur operasional, rekan kerja, tipe pekerjaan dan komunikasi. Dalam hal ini, kepuasan kerja pada dasarnya merupakan hal yang bersifat individual, setiap individu memiliki tingkat kepuasan yang berbeda-beda sesuai dengan sistem nilai-nilai yang berlaku pada dirinya dan masing-masing individu, sehingga kepuasan kerja yang dirasakan oleh karyawan lakilaki ataupun perempuan pun dapat berbeda. Dari permasalahan ini peneliti ingin mengetahui gaya kepemimpinan yang digunakan oleh masing-masing atasan baik laki-laki ataupun perempuan dan bagaimana tingkat kepuasan kerja karyawan lakilaki dan perempuan.

\section{Metode Penelitian}

Penelitian ini menggunakan metode kuantitatif karena data penelitian berupa angka-angka dan menggunakan statistika (Sugiyono, 2010). Desain penelitian ini adalah ex-post facto. Hal ini dikarenakan pada penelitian ex-post facto da'ta sudah terdapat di dalam kelompok subjek yang diteliti, dan bukan merupakan hasil dari suatu perlakuan khusus. Dengan kata lain, dalam penelitian ini peneliti tidak dapat memanipulasi data yang diperoleh dari kelompok sampel (Rangkuti, 2009). Adapun ciri-ciri populasi dari penelitian ini adalah karyawan yang bekerja di suatu perusahaan BUMN dengan masing-masing memiliki atasan laki-laki dan perempuan. Berdasarkan tujuan dalam penelitian ini maka karakteristik sampel penelitian yang diambil oleh peneliti adalah sebagai berikut:

1. Karyawan yang bekerja di PERUM PERUMNAS Regional III

2. Karyawan dengan atasan laki-laki dan perempuan

3. Berjenis kelamin pria atau wanita

Alat pengumpul data untuk gaya kepemimpinan adalah skala LBDQ XII (Leadership Behavior Decription Questionnare) dari Ohio State University. Sedangkan alat pengumpulan data untuk kepuasan kerja dalam penelitian ini adalah skala JSS (Job Satisfaction Survey). Uji statistik yang digunakan adalah analisis varians dua jalur dengan program komputer SPSS.

\section{Hasil dan Diskusi}

Penelitian ini dilakukan terhadap 129 responden yang dipimpin oleh atasan laki-laki dan atasan perempuan di PERUM PERUMNAS Regional III. Hasil perhitungan yang dilakukan dengan menggunakan analisis varians dua jalur SPSS for windows 17.0 dan didapatkan hasil sebagai berikut: 
Jurnal Penelitian Pengukuran Psikologi Vol. 2 No.2. Oktober 2013 Tabel Hasil Perhitungan Analisis Varians

\begin{tabular}{|c|c|c|c|c|c|}
\hline \multicolumn{6}{|c|}{$\begin{array}{c}\text { Tests of Between-Subjects Effects } \\
\text { Dependent Variable:KK }\end{array}$} \\
\hline Source & $\begin{array}{l}\text { Type III } \\
\text { Sum of } \\
\text { Squares }\end{array}$ & $\mathrm{df}$ & $\begin{array}{c}\text { Mean } \\
\text { Square }\end{array}$ & $\mathrm{F}$ & Sig. \\
\hline $\begin{array}{l}\text { Correcte } \\
\text { d Model }\end{array}$ & $\begin{array}{c}39706.3 \\
20^{\mathrm{a}}\end{array}$ & 90 & $\begin{array}{c}441.18 \\
1\end{array}$ & $\begin{array}{c}2.62 \\
8\end{array}$ & .001 \\
\hline Intercept & $\begin{array}{c}121444 \\
3.648\end{array}$ & 1 & $\begin{array}{c}121444 \\
3.648\end{array}$ & $\begin{array}{l}7233 \\
.656\end{array}$ & .000 \\
\hline IS & $\begin{array}{c}8119.29 \\
7\end{array}$ & 16 & $\begin{array}{c}507.45 \\
6\end{array}$ & $\begin{array}{c}3.02 \\
3\end{array}$ & .003 \\
\hline $\mathrm{C}$ & $\begin{array}{c}14801.1 \\
07\end{array}$ & 26 & $\begin{array}{c}569.27 \\
3\end{array}$ & $\begin{array}{c}3.39 \\
1\end{array}$ & .000 \\
\hline IS $* \mathrm{C}$ & $\begin{array}{c}13559.3 \\
93\end{array}$ & 47 & $\begin{array}{c}288.49 \\
8\end{array}$ & $\begin{array}{c}1.71 \\
8\end{array}$ & .044 \\
\hline Error & $\begin{array}{c}6379.74 \\
2\end{array}$ & 38 & $\begin{array}{c}167.88 \\
8\end{array}$ & & \\
\hline Total & $\begin{array}{c}246427 \\
4.000\end{array}$ & 129 & & & \\
\hline $\begin{array}{l}\text { Correcte } \\
\text { d Total }\end{array}$ & $\begin{array}{c}46086.0 \\
62\end{array}$ & 128 & & & \\
\hline
\end{tabular}

Berdasarkan hasil tersebut, maka kesimpulan yang dapat diambil adalah:

1. Pada variabel initiating structure diperoleh sig. 0,003 . Hal ini menunjukan bahwa nilai $p<0,05$ maka Ho ditolak dan Ha diterima. Artinya terdapat perbedaan kepuasan kerja yang signifikan ditinjau dari gaya kepemimpinan initiating structure.

2. Pada variabel consideration diperoleh sig. 0,000. Hal ini menunjukan bahwa nilai $\mathrm{p}<0,05$ maka Ho ditolak dan $\mathrm{Ha}$ diterima. Artinya terdapat perbedaan kepuasan kerja yang signifikan ditinjau dari gaya kepemimpinan consideration.

3. Pada tabel terlihat interaksi antara variabel initiating structure dan consideration diperoleh sig. 0,044 . Hal ini menunjukan bahwa nilai $\mathrm{P}<0,05$ maka Ho ditolak dan Ha diterima. Artinya terdapat perbedaan kepuasan kerja yang signifikan ditinjau dari interaksi antara gaya kepemimpina initiating structure dan consideration.

Pada perhitungan analisis varians ini digunakan untuk menganalisis secara keseluruhan dan hasil penelitian menunjukan bahwa terdapat perbedaan pada interaksi antara initiang structure dan consideration. Hal ini sesuai dengan penelitian terkait yang mengatakan bahwa gaya kepemimpinan consideration lebih memberikan efek positif terhadap kepuasan kerja karyawan dibandingkan dengan gaya kepemimpinan initiating structure. Dalam beberapa studi, para karyawan lebih banyak mendapatkan kepuasan bekerja dengan pemimpin yang sangat berkepentingan dengan pemimpin yang tidak terlalu berorientasi dengan pekerjaan (Wexley \& Yuki, 2005).

Kemudian analisis dapat dilanjutkan dengan menggunakan t-test (Sugiyono, 2010). Analisis ttest ini digunakan untuk melihat pada faktor gaya kepemimpinan dan kepuasan kerja.

Untuk faktor gaya kepemimpinan perhitungannya dilakukan dengan menggunakan SPSS for windows 17.0 dan didapatkan hasil sebagai berikut:

Tabel 4.13

Independent Sample T-test Gaya kepemimpinan

\begin{tabular}{cccc}
\hline Variabel & \multicolumn{2}{c}{$\begin{array}{c}\text { Equality of } \\
\text { Variance }\end{array}$} & Interpretasi \\
\cline { 2 - 3 } & $\mathbf{P}$ & Sig & \\
\hline Gaya & 0,805 & 0,05 & Ho diterima
\end{tabular}

Kepemimpinan

Berdasarkan hasil tersebut maka terlihat bahwa $\mathrm{p}>0,05$ sehingga hasil penelitian menunjukan tidak terdapat perbedaan gaya kepemimpinan yang signifikan antara atasan lakilaki dan atasan perempuan. Hal ini dapat dipengaruhi oleh hubungannya dengan bawahan, karena baik atasan laki-laki ataupun atasan perempuan dalam proses interaksinya dengan bawahan sama-sama memiliki upaya untuk mempengaruhi bawahannya agar berperilaku sesuai dengan harapannya. Gaya kepemimpinan yang digunakan oleh atasan laki-laki ataupun atasan perempuan tidak hanya dipengaruhi oleh jenis kelamin atau gender. Akan tetapi, juga disesuaikan dengan kondisi bawahannya (Munandar, 2008). Faktor lain inilah yang dapat menjadi salah satu alasan yang menyebabkan gaya kepemimpinan antara atasan laki-laki dan atasan perempuan tidak terdapat perbedaan.

Untuk faktor kepuasan kerja perhitungannya dilakukan dengan menggunakan SPSS for windows 17.0 dan didapatkan hasil sebagai berikut:

Tabel 4.14

Independent Sample T-test Kepuasan Kerja

\begin{tabular}{cccc}
\hline Variabel & \multicolumn{2}{c}{$\begin{array}{c}\text { Equality Of } \\
\text { Variance }\end{array}$} & Interpretasi \\
\cline { 2 - 3 } & $\mathbf{P}$ & Sig & \\
\hline $\begin{array}{c}\text { Kepuasan } \\
\text { Kerja }\end{array}$ & 0,146 & 0,05 & Ho diterima \\
\hline
\end{tabular}

Berdasarkan hasil tersebut maka terlihat bahwa $p>0,05$ sehingga hasil penelitian menunjukan tidak terdapat perbedaan kepuasan kerja yang signifikan 
antara karyawan laki-laki dan karyawan perempuan. Hal ini didukung oleh penelitian terkait yaitu faktor demografi jenis kelamin tidak mempengaruhi tinggi atau rendahnya kepuasan kerja karyawan tetapi faktor-faktor lain yang ada hungannya dengan jenis kelamin, seperti jabatan (Hulin \& Smith, 1964). Selain itu, penemuan lainnya yang menunjukan bahwa tidak ada perbedan yang signifikan pada kepuasan kerja antara karyawan laki-laki dan perempuan (De Vaus \& Mc Allister, 1989; Witt \& Nye, 1992; Cano \& Miller, 1992; Mannheim, 1983 dan Smith, Smits \& Hoy, 1998). Hal ini dapat dikarenakan peran dari karakteristik kepribadian yang berkaitan dengan gender dalam kepuasan kerja dan perilaku pemimpin.

Penelitian ini memiliki beberapa keterbatasan yaitu keterbatasan dalam mencari referensi atau literatur mengenai gaya kepemimpinan studi Ohio yang lebih luas. Selain itu, penulis mengalami keterbatasan dalam penyebaran kuesioner sebab dari pihak perusahaan tidak dapat membantu peneliti untuk dapat menyebarkan kuesioner ke cabang-cabang dari PERUM PERUMNAS Regional III lainnya.

\section{Kesimpulan}

Berdasarkan hasil pengujian hipotesis secara statistik, dapat disimpulkan bahwa terdapat perbedaan kepuasan kerja yang signifikan ditinjau dari interaksi antara gaya kepemimpinan initiating structure dan consideration, sehingga perhitungan dilanjutkan dengan memperhitungkan pada faktor gaya kepemimpinan dan kepuasan kerja. Pada faktor gaya kepemimpinan menunjukan bahwa tidak terdapat perbedaan gaya kepemimpinan antara atasan laki-laki dan atasan perempuan, begitu juga halnya pada faktor kepuasan kerja yang menunjukan bahwa tidak terdapat perbedaan yang signifikan antara kepuasan kerja pada karyawan laki-laki dan karyawan perempuan.

Peneliti selanjutnya dapat lebih mengembangkan penelitian mengenai gaya kepemimpinan dan kepuasan kerja ini dengan mengaitkan variable lainnya sehingga dapat menambah wawasan mengenai psikologi industri dan organisasi. Selain itu, alangkah baiknya jika peneliti selanjutnya dapat menanyakan pengalaman kerja dari responden tidak hanya lama bekerja, sebab hal tersebut dapat mendukung untuk melihat kepuasan kerja pada karyawan tersebut.

\section{Daftar Pustaka}

Anoraga, P., \& Suyati, S. (1995). Psikologi Industri dan Sosial. Jakarta: Pustaka Jaya.

As'ad, M. (1998). Psikologi Industri: Seri Sumber Daya Manusia (4rd ed.). Yogyakarta: Liberty.

Atmojo, M. (2012). The Influence of Transformational Leadership on Job Satisfaction, Organizational Commitment, and Employee Performance. Journal of Business Studies.

Azwar, S. (2012). Penyusunan Skala Psikologi (2rd ed.). Yogyakarta: Pustaka Belajar

Bass, B. M. (1981). Stogdill's Handbook of Leadership. New York: Free Press.

Baron, A. R., \& Byrne, D., (2004). Psikologi Sosial (10rd ed.). Jakarta: Erlangga.

Brahmasari, A. I., \& Suprayetno, A. (2008). Pengaruh Motivasi Kerja, Kepemimpinan dan Budaya Organisasi Terhadap Kepuasan Kerja Karyawan serta Dampaknya pada Kinerja Perusahaan, (ONLINE), http://www.scribd.com/doc/19726858/Man08100204. Jurnal Manajemen dan Kewirausahaan di akses pada tanggal 12 September 2012 jam 22:15.

Dipboye, R. L., Smith, C. S., \& Howell, W. C. (1994). Understanding An Industrial and Integrated Organizational Approach Psychology. New York: Harcourt Brace College.

Harmandini, F. (2010). Boss Perempuan Tidak Disukai karena Moody. http://female.kompas.com/read/2010/08/13/11 284932/Bos.Perempuan.Tidak.Disukai.karena .Moody. diakses pada tanggal 25 Februari 2012 jam 20:35.

Hersey, P., \& Blanchard, K. (1988). Management of Organizational Behavior: Utilizing Human Resource (5rd ed.). London: Prentice Hall.

Kreitner, R., \& Kinicki, A. (2004). Organizational Behavior (6rd ed.). New York: McGraw-Hill.

Lok, P., \& Crowford, J. (2004). The Effect of Organisational Culture and Leadership Style on Job Satisfaction and Organisational Commitment. Journal of Management Development.

Munandar, A. S. (2001). Psikologi Industri dan Organisasi. Jakarta: UI Press.

Papalia, D. E., Old, S. W., \& Feldman, R. D. (2008). Human Development (Psikologi Perkembangan) (9rd ed.). Jakarta: Kencana. 
Jurnal Penelitian Pengukuran Psikologi Vol. 2 No.2. Oktober 2013

Rangkuti, A. A., \& Suryaratri, R. D. (2009).

Statistika Inferensial untuk Penelitian

Psikologi dan Pendidikan. Jakarta.

Rangkuti, A. A. (2012). Teknik Analisis Data

Penelitian Kuantitatif Aplikasi dengan

Program SPSS. Jakarta.

Rehman, S., Mansoor, M., \& Bilal, R. U. (2012). The Impact of Leadership Styles on Job Satisfaction at Work Place. Journal of Business and Management.

Riaz, A., \& Haider, M. H. (2010). Role of Transformational and Transactional Leadership on Job Satisfaction and Career Satisfaction. Journal of Business and Economic Horizons.

Spector, P. E. (1985). Measurement of Human Service Staff Satisfaction Survey. Journal of Community Pschology.

Spector, P. E. (1997). Job Satisfaction: Application, Assessment, Causes, and Consequences. London: SAGE Publication.

Stogdill, R. M. (1974). Handbook of Leadership: A Survey of Theory and Research. New York: Free Press.

Sugiyono. (2010). Metode Penelitian Pendidikan: Pendekatan Kuantitatif, Kualitatif, dan R \& D. Bandung: Alfabeta.

Thoha, M. (2012). Kepemimpinan dalam Manajemen. Jakarta: Rajawali Pers

Watson, A. M., Thompson, L. F., \& Meade, A. W. (2007, April). Measurement Invariance of The Job Satisfaction Survey Across Work

Contexts. Paper Presented at the 22nd Annual
Meeting of the Society for Industrial and Organizational Psychology. New York.

Wexley, K. N., \& Yuki, A. (2005). Perilaku Organisasi dan Psikologi Personalia. Jakarta: Rineka Cipta

Wijono, S. (2010). Psikologi Industri dan Organisasi: Dalam suatu Bidang Gerak Psikologi Sumber Daya Manusia. Jakarta: Kencana. 